\title{
Experimental and FEM studies on mechanical properties of single-lap adhesive joint with dissimilar adherends subjected to impact tensile loadings
}

\author{
Lijuan Liao $^{\mathrm{a}, *}$, Toshiyuki Sawa ${ }^{\mathrm{b}}$, Chenguang Huang ${ }^{\mathrm{a}}$ \\ ${ }^{a}$ Key Laboratory for Mechanics in Fluid Solid Coupling Systems, Institute of Mechanics, Chinese Academy of Sciences, Beijing 100190, People's Republic of China \\ ${ }^{\mathrm{b}}$ Graduate School of Engineering, Hiroshima University, 1-4, Kagamiyama, Higashihiroshima, Hiroshima 739-8527, Japan
}

\section{A R T I C L E I N F O}

\section{Article history:}

Accepted 7 February 2013

Available online 19 February 2013

Keywords:

Single-lap adhesive joints

Dissimilar adherends

Impact tensile loadings

Interface stress distributions

Stress wave propagations

\begin{abstract}
A B S T R A C T
The rupture initiation position, the stress wave propagations and interface stress distributions of the single-lap adhesive joint with dissimilar adherends under impact tensile loadings are analyzed via experiments combined with FEM calculations taking account of the strain rate dependency property of the adhesive. It is obtained that rupture initiates at the interface of the adherend with higher Young's modulus (steel side in this study) in the joint under impact tensile loadings, which shows the opposite characteristic in the same type of joint under static loadings. A fairly good agreement is observed between the experimental measured and FEM calculated results. In addition, it is also found that the strength of the joint with dissimilar adherends is smaller than that of the joint with similar adherends when the joint is subjected to the impact tensile loadings owing to the different extent of the wave impedance mismatch which depends on the material properties. Finally, the design guideline for the single-lap adhesive joint is summarized and provided.
\end{abstract}

(c) 2013 Elsevier Ltd. All rights reserved.

\section{Introduction}

It is well known that the adhesive, which is provided with a prominent advantage of joining with dissimilar materials even non-metal [1], has been used widely to join various materials together to meet various requirements in automotive and aerospace industries, particularly for joining glass fiber reinforced plastics (GFRP) to metals [2]. Sawa et al. have studied the properties of the adhesive joints with dissimilar adherends under static loadings, including the butt [3], single-lap [4] and steppedlap [5] adhesive joints. They concluded that the rupture initiates at the interface of the adherend with higher Young's modulus in the butt (under tensile loadings) and the stepped-lap (under bending moment) adhesive joints. Meanwhile, the rupture initiates at the interface of the adherend with smaller Young's modulus in the single-lap (under tensile loadings) adhesive joints because of the peel stresses.

Generally, the adhesive joints are subjected to short duration dynamic loadings in service [2]. Early investigations [6,7] gave the assessment for measuring the impact strength of the adhesive joints. Sato et al. [8-10] carried out a series of researches about the impact behaviors of the adhesive joints under impact loadings. Yokoyama et al. [11,12] introduced the split Hopkinson bar techniques which are used widely in the impact experiments of

\footnotetext{
${ }^{*}$ Corresponding author. Tel.: +86 108254 4291; fax: +86 1082544256 .

E-mail address: liaohuanxin@yahoo.com.cn (L. Liao).
}

the adhesive joints. Sawa et al. studied the properties of the single-lap adhesive joints with similar [13] and dissimilar [14] adherends, plates butt adhesive joints [15], cylindrical butt adhesive joints with similar [16] and dissimilar hollow cylinders [17] under impact loadings. Maheri and Adams [18] researched the dynamic shear modulus in thick adherend shear test specimens under a high frequency. Vaidya et al. [19] carried out the experimental-numerical studies of the responses of the single-lap adhesive joints under transverse impact loadings. Goglio and Rossetto [20] examined the impact rupture of the adhesive joints under different stress combinations. Challita and Othman [21] examined the influence of material, geometrical and dynamic parameters on the accuracy of the SHPB results of the double-lap adhesive joints.

In the present study, in order to establish a rational design method for single-lap adhesive joints, it is necessary to know the different mechanical properties of the joints with similar and dissimilar adherends under impact tensile loadings as well as static loadings to provide design guideline under definite working conditions via experiments and FEM calculations. The strain rate dependency property of the adhesive, the strain responses of dissimilar adherends and strengths of the joints subjected to the impact tensile loadings are measured experimentally. Meanwhile, the interface stress wave propagations and distributions of the same type joints are examined using FEM calculations taking the adhesive strain rate sensitivity into consideration. In addition, the interface stress distributions of the joint under sudden loadings are also examined as a special condition for distinguishing the 
different properties compared with the joint under static conditions. Furthermore, the characteristics obtained under impact/ static conditions of the joint with similar/dissimilar adherends are compared with each other. Finally, the design guideline for the single-lap adhesive joint is summarized and provided.

\section{Experiments and FEM calculations}

\subsection{Mechanical properties of the adhesive and the adherends}

The adhesive employed in the present study is $3 \mathrm{M}^{\mathrm{TM}}$ ScotchWeld $^{\mathrm{TM}}$ Epoxy Adhesives $1838 \mathrm{~B} / \mathrm{A}$ (SW1838). SW1838 is twopart, room temperature curing structural adhesives with high shear strengths and excellent environmental resistance [22]. The strength prediction of the joint under static loadings, which is determined when the maximum value of the maximum principal stress reaches the measured rupture stress of the adhesive in the vicinity of the adhesive interface edges, is based on the measured stress-strain curve of the adhesive under static condition $[5,23]$. However, the plastic flow deformation behaviors of structural adhesives, which are sensitive to the strain rate, should be taken into account to evaluate the impact strengths of the adhesive joints.

In this study, the Cowper-Symonds constitutive model taking into account the strain rate dependency is applied to describe the plastic flow characteristic of the structural adhesive [24], which is the versatile model in various analyses. Iwamoto et al. [25] and Nagai et al. [26] have examined the deformation behavior and strain rate sensitivity of epoxy resin (SW1838) using experiments (INSTRON-type material testing machine and a split Hopkinson bar apparatus) and FEM simulations in the entire range of strain rate from $10^{-4} / \mathrm{s}$ to $10^{3} / \mathrm{s}$. Fig. 1 shows the true stress-true strain curves of the structural adhesive SW1838 measured experimentally (solid line), and the comparison with the FEM calculations (dash line) using Cowper-Symonds model in the strain rate range from $10^{-3} / \mathrm{s}$ to $10^{\circ} / \mathrm{s}$, which are obtained from the previous investigations [27]. It can be observed that the yield stress of the bulk adhesive increases as the strain rate increases. In addition, it also can be found that the strain rate dependency behavior of the adhesive can be expressed by Cowper-Symonds model calculations appropriately.

In the present study, same experimental setups and analytical methods [25-27] are adopted to examine the plastic flow deformation behavior of the adhesive under the environment temperature $293 \mathrm{~K}$. Based on the experimental results considering

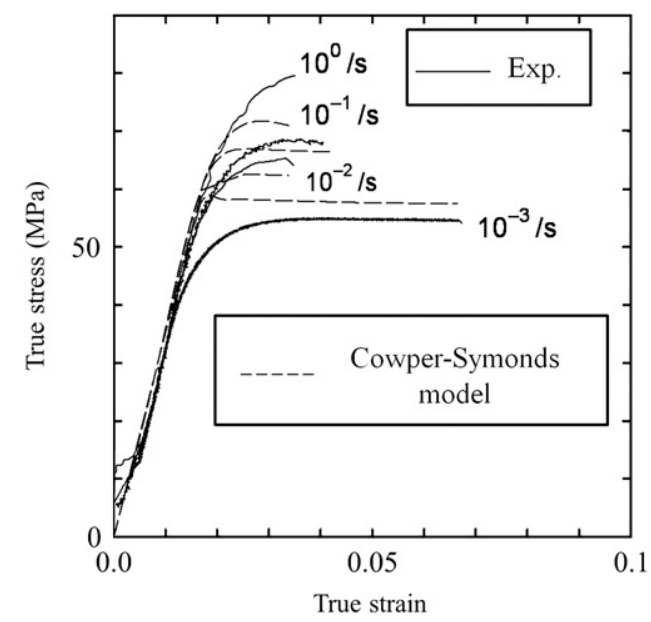

Fig. 1. Comparison of true stress-true strain curves of the structural adhesive measured experimentally and Cowper-Symonds model calculations [27].
Table 1

Material parameters of adhesive (SW1838)

\begin{tabular}{lllllll}
\hline$C$ & $P$ & $k(\mathrm{MPa})$ & $n$ & $\rho\left(\mathrm{kg} / \mathrm{m}^{3}\right)$ & $E(\mathrm{GPa})$ & $v$ \\
\hline 1.026 & 1.506 & 64.522 & 0.046 & $1.13 \times 10^{3}$ & 3.34 & 0.38 \\
\hline
\end{tabular}

Table 2

Material parameters of dissimilar adherends (aluminum-steel).

\begin{tabular}{lccc}
\hline & $\rho\left(\mathrm{kg} / \mathrm{m}^{3}\right)$ & $E(\mathrm{GPa})$ & $v$ \\
\hline Aluminum (A5052) & $2.6 \times 10^{3}$ & 70 & 0.34 \\
Steel (S45C) & $7.8 \times 10^{3}$ & 206 & 0.31 \\
\hline
\end{tabular}

different strain rates, the material parameters of the adhesive can be obtained as shown in Table 1, where $C$ and $P$ are the CowperSymonds strain rate parameters, $k$ is the strength coefficient, $n$ is the hardening coefficient, $\rho$ is the density, $E$ is Young's modulus and $v$ is Poisson's ratio.

The aluminum (A5052) sheets and the steel (S45C) sheets are chosen as adherends. Table 2 shows the material parameters of dissimilar adherends (aluminum-steel) of the single-lap adhesive joints.

\subsection{Impact tensile tests}

The strain responses and the strengths of the single-lap adhesive joints with dissimilar adherends (aluminum-steel) subjected to the impact tensile loadings were measured via series of drop weight impact tests. Fig. 2 shows the dimensions of the specimens with strain gauges (A and B) used in the experiments. The dimensions of each adherend are the same: the effective length of the adherends is $100 \mathrm{~mm}$, the width is $20 \mathrm{~mm}$ and the thickness is $10 \mathrm{~mm}$. The thickness of the adhesive layer is chosen as $0.1 \mathrm{~mm}$. The overlap length of the dissimilar adherends (aluminum-steel) is $25 \mathrm{~mm}$. Strain gauges (A for Aluminum side $\&$ B for steel side), with the dimensions of $5.0 \mathrm{~mm}$ in length and $2.5 \mathrm{~mm}$ in width, are glued at the opposite surfaces of the dissimilar adherends as shown in Fig. 2. The strain responses in the tensile direction are measured using them, which are located in the middle along the width of the joint.

The joints are placed on the testing equipment as shown in Fig. 3 and are subjected to the impact loadings by dropping a weight-hammer [28]. The impact component with a mass of $18.5 \mathrm{~kg}$ is dropped to the joint from a height $H$ and then with the contact initial velocity $V$ when it impacts on the upper end of the jigs. The compressive impact load can be turned into tensile impact load using the two combined jigs. For the initial impact velocity $V$, which is defined using the initial height of the dropping weight-hammer $H$, is expressed as $V=\sqrt{2 g H}$ (where ' $g$ ' is acceleration of gravity). During the experiments, the aluminum adherend is located at the upper and the steel adherend is located at the lower, as shown in Fig. 3. The strain responses (tested by strain gauges $A$ and $B$ glued on the surfaces of the dissimilar adherends, respectively) were recorded using an analyzing recorder and dynamic amplifiers. In addition, the impact rupture strengths of specimens, characterized by the impact energy $I E=1 / 2 M V^{2}$, were also measured.

\subsection{D FEM calculations}

The dimensions and constraints of the FEM model adopted in the present paper are defined in Cartesian coordinates $(x, y, z)$ system. As shown in Fig. 4, Adherend [I] (aluminum) and 

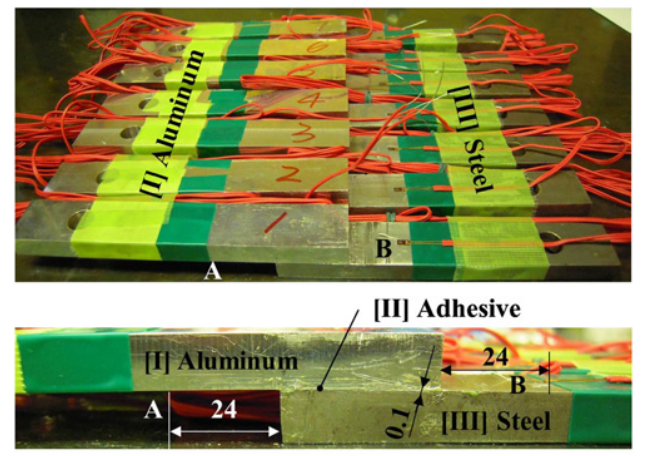
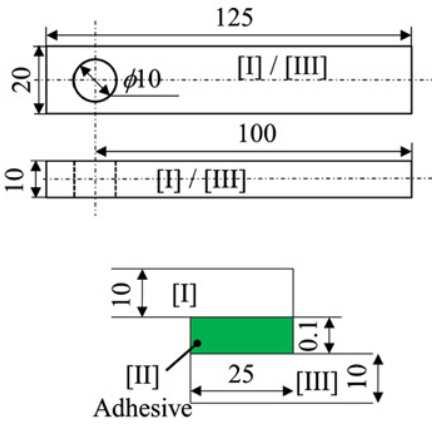

Fig. 2. Dimensions of the test specimens (Unit: $\mathrm{mm}$ ).
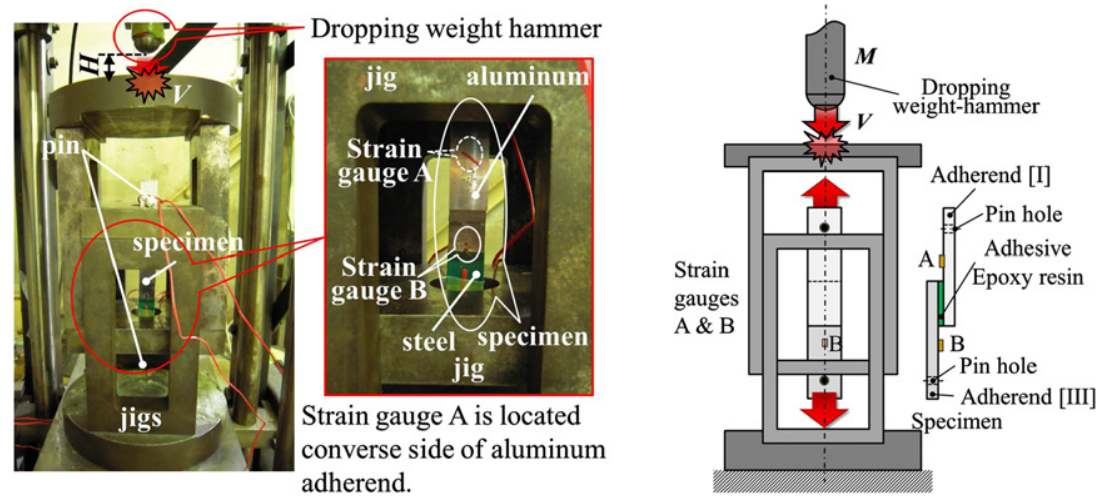

Fig. 3. Experimental setup for impact tensile tests.

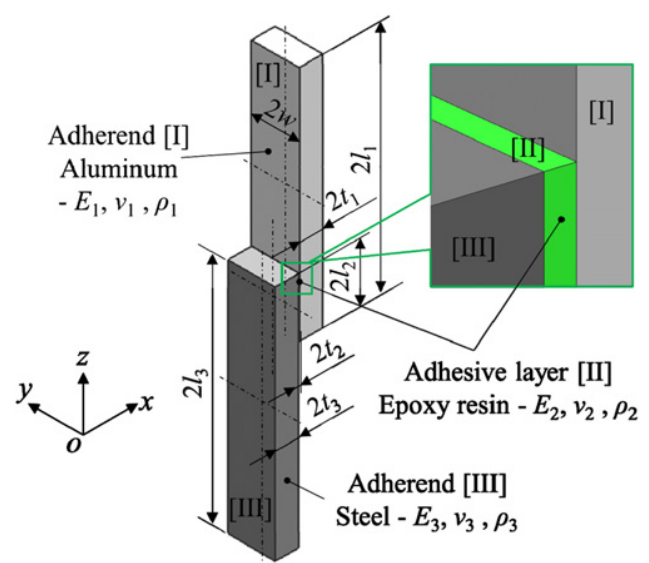

Fig. 4. Model and designations of dimensions for the FEM calculations for single-lap adhesive joint with dissimilar adherends (aluminum-steel).

adherend [III] (steel) are adhered to the adhesive layer [II] (epoxy resin) at the ends. In FEM calculations, the impact tensile loadings are applied to the free end of the adherend [III] (steel) connected with a mass equivalent to the dropping weigh-hammer with the initial impact velocity $V$ and the gravity acceleration $g$. For the boundary conditions of the single-lap adhesive joint with dissimilar adherends subjected to the impact tensile loadings, the definitions are as follows (as shown in Fig. 5): The upper end of the adherend [I] (aluminum) is fixed in all the directions. The lower end of the adherend [III] (steel) is fixed both in the $x$-direction and $y$-direction. It can only move through the $z$-direction when the joint is subjected to the impact tensile loading. The connected mass, which is also fixed both in the $x$-direction and $y$-direction, moves along the $z$-direction. The material of the adherends [I] and [III] are assumed to be linear isotropic elastic model using destiny $\rho$, Young's modulus $E$ and Poisson's ratio $v$. Cowper-Symonds model [24], which is nonlinear inelastic sensitive to the strain rate, is applied to define adhesive layer [II]. The values of the dimensions and material parameters defined are the same as those used in the experiments.

Fig. 6 shows an example of mesh divisions in FEM for the joint with dissimilar adherends (aluminum-steel) subjected to the impact tensile loadings. 3D SOLID164 elements are used. In particular, the minimum size of the element at the interfaces is chosen as $10 \mu \mathrm{m}$. The numbers of elements and nodes employed are 8000 and 10,175, respectively. The FEM code (ANSYS/LSDYNA) employed is explicit. In the present study, impact velocity is assumed to be small, so that it can be considered as dynamic problem with low strain rate.

\section{Results and discussion}

\subsection{Experimental results}

Fig. 7 shows the comparisons of the strain responses between the experimental (designations ' $O$ ' and ' $\square$ ') and FEM calculated (solid and dash lines) results of the single-lap adhesive joint with dissimilar adherends (aluminum-steel) subjected to the impact tensile loadings. As shown in Fig. 7, the ordinate represents the strain $\varepsilon_{z}$ in the $z$-direction, which is the maximum value (peak value of the strain wave) of the strain in the $z$-direction at point $A$ where the strain gauge was glued at the surface of the adherend [I] (aluminum) and at point B where the strain gauge was glued at the surface of the adherend [III] (steel), respectively. The abscissa is the initial height of the dropping weight hammer $H$. The FEM 


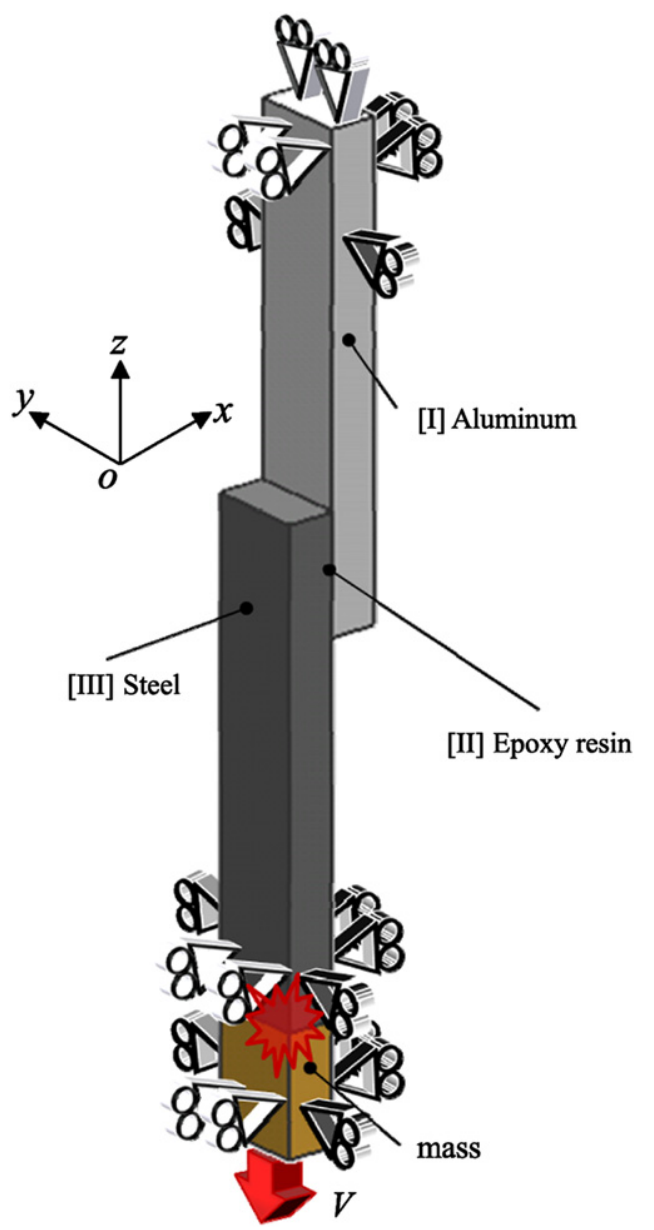

Fig. 5. Boundary conditions in FEM calculations for single-lap adhesive joint with dissimilar adherends (aluminum-steel) under impact tensile loadings.

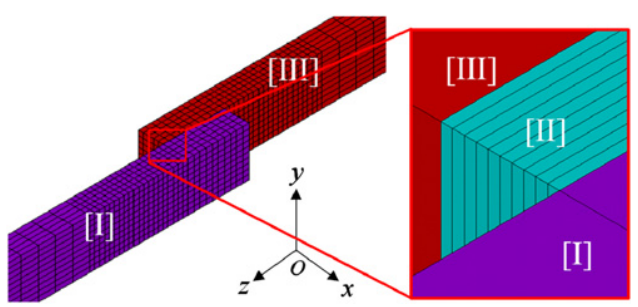

Fig. 6. An example of the element divisions in FEM for single-lap adhesive joint with dissimilar adherends (aluminum-steel).

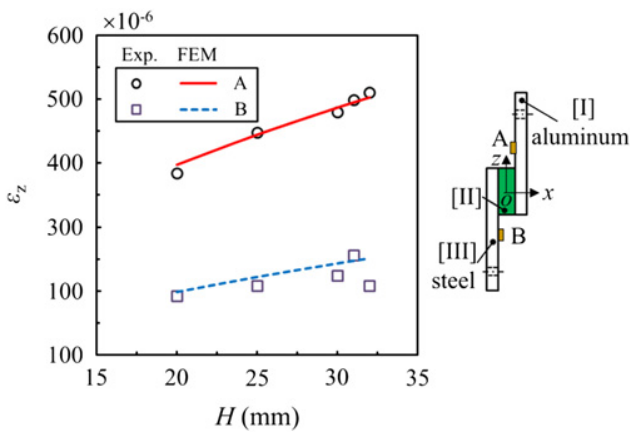

Fig. 7. Comparison of the strain responses between the experimental and FEM calculated results (the strain responses in the $z$-direction were measured using strain gauges glued at point $\mathrm{A}$ for aluminum side and at point $\mathrm{B}$ for steel side, respectively).
Table 3

Measured joint strength under impact tensile loadings.

\begin{tabular}{llllllllll}
\hline$H(\mathrm{~mm})$ & IE $(\mathrm{J})$ & \multicolumn{9}{l}{ No. (Specimens) } \\
\cline { 3 - 9 } & & 1 & 2 & 3 & 4 & 5 & 6 & 7 \\
\hline 20 & 3.626 & $\times$ & $\times$ & $\times$ & $\times$ & $\times$ & $\times$ & $\times$ \\
25 & 4.533 & $\times$ & $\times$ & $\times$ & $\times$ & $\times$ & $\times$ & $\times$ \\
30 & 5.439 & $\times$ & $\times$ & $\times$ & $\times$ & $\times$ & $\times$ & $\times$ \\
31 & 5.620 & $\times$ & $\times$ & $\times$ & $\times$ & $\times$ & $\times$ & $\times$ \\
32 & 5.802 & $\times$ & $\circ$ & $\times$ & $\circ$ & $\circ$ & $\times$ & $\times$ \\
33 & 5.983 & $\circ$ & $\circ$ & $\circ$ & $\circ$ & $\circ$ & $\circ$ & $\circ$ \\
\hline
\end{tabular}

Notes: ( $\times$ ) No-rupture, ( $($ ) Rupture.

calculated results are in good agreement with the corresponding experimental results taking account of the strain responses.

From the comparison, it can be observed that the results show the increasing trend of the strain values as the initial height of dropping weight-hammer $H$ increases. In addition, it can be obtained that the strain response values at point $A$ are larger than those at point $\mathrm{B}$ at the corresponding impact initial height $H$. It can be assumed that the strain energy of the adherend [I] (aluminum) with smaller Young's modulus is higher than that of the adherend [III] (steel) with higher Young's modulus.

Table 3 shows the experimental results for the joint strength estimation. In the experiments, the initial height of the dropping weight-hammer $H$ was varied as $20 \mathrm{~mm}, 25 \mathrm{~mm}, 30 \mathrm{~mm}, 31 \mathrm{~mm}$, $32 \mathrm{~mm}$ and $33 \mathrm{~mm}$, respectively. Seven (denoted as 1-7) specimens were subjected to the impact tensile loadings with the variation of the initial height $H$ for each specimen of single-lap joint. The designation ' $x$ ' indicates no-rupture; while the designation ' $O$ ' demonstrates that the rupture occurs in the experiments. The value IE (defined as $1 / 2 M V^{2}$ ), which is used as description of the rupture strength, is varied according to the variation of the initial height of the dropping weight-hammer $H$. The impact rupture strength of the single-lap adhesive joint with dissimilar adherends (aluminum-steel), as an example in this study, can be estimated over $5.983 \mathrm{~J}$ $(M=18.5 \mathrm{~kg}, H=33 \mathrm{~mm}, V=804 \mathrm{~mm} / \mathrm{s})$.

\subsection{Results of FEM calculation}

In the FEM calculations, the weight-hammer was dropped from a height $H=25 \mathrm{~mm}$ and the initial impact velocity ( $V=$ $\sqrt{2 g H}$ ) of the mass (as shown in Fig. 5) was chosen as $V=700 \mathrm{~mm} / \mathrm{s}$.

Fig. 8 shows 18 key points, which are denoted as $\mathrm{p}_{1}, \mathrm{p}_{2}, \mathrm{p}_{3}, \mathrm{p}_{4}, \mathrm{p}_{5}$, $\mathrm{p}_{6}, \mathrm{p}_{7}, \mathrm{p}_{8}, \mathrm{p}_{9}, \mathrm{p}_{10}, \mathrm{p}_{11}, \mathrm{p}_{12}, \mathrm{p}_{13}, \mathrm{p}_{14}, \mathrm{p}_{15}, \mathrm{p}_{16}, \mathrm{p}_{17}$ and $\mathrm{p}_{18}$, to describe the stress wave propagations and interface stress distributions in the adhesive layer of the single-lap adhesive joint with dissimilar adherends (aluminum-steel) subjected to the impact tensile loadings to predict the rupture position. Table 4 shows the positions of the eighteen points $\left(\mathrm{p}_{1}-\mathrm{p}_{18}\right)$. From the isometric view point, the upper, middle and lower interfaces can be counted the six points in anticlockwise, respectively. Owing to the singularity, the stresses should be examined at a selected distance from the singular point [29-33]. In the present study, the positions in the vicinity of the interface edges are chosen as $z / l_{2}= \pm 0.8$.

Fig. 9 shows the maximum principal stress $\sigma_{1}$ wave propagations at the eighteen points $\left(\mathrm{p}_{1}-\mathrm{p}_{18}\right)$, those are at the upper $\left(\mathrm{p}_{1}-\mathrm{p}_{6}\right)$, middle $\left(\mathrm{p}_{7}-\mathrm{p}_{12}\right)$ and lower $\left(\mathrm{p}_{13}-\mathrm{p}_{18}\right)$ interfaces $\left(x / t_{2}=1.0\right.$, adhered to [I] \& $x / t_{2}=0.0 \& x / t_{2}=-1.0$, adhered to [III] ) of the single-lap adhesive joint with dissimilar adherends (aluminumsteel) subjected to the impact tensile loadings, respectively. The ordinate is the value of the maximum principal stress $\sigma_{1}$. The abscissa is the elapsed time $t$ simulated in ANSYS/LS-DYNA, which is chosen as $0.3 \mathrm{~ms}$. 

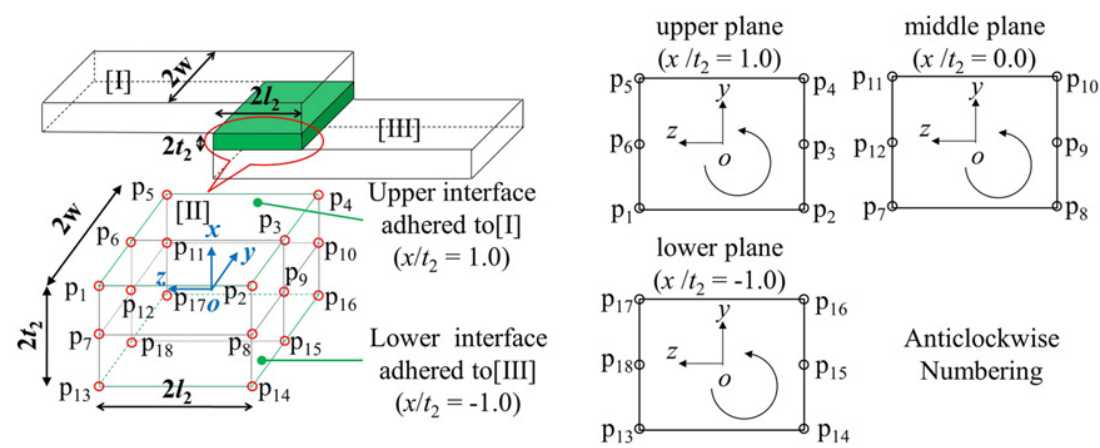

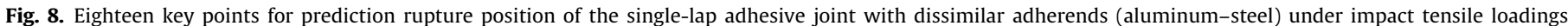
(in anticlockwise numbering).

Table 4

Positions of the eighteen points $\left(\mathrm{p}_{1}-\mathrm{p}_{18}\right)$.

\begin{tabular}{llllllll}
\hline No. & $x / t_{2}$ & $y / w$ & $z / l_{2}$ & No. & $x / t_{2}$ & $y / w$ & $z / l_{2}$ \\
\hline $\mathrm{p}_{1}$ & 1.0 & -1.0 & 0.8 & $\mathrm{p}_{10}$ & 0.0 & 1.0 & -0.8 \\
$\mathrm{p}_{2}$ & 1.0 & -1.0 & -0.8 & $\mathrm{p}_{11}$ & 0.0 & 1.0 & 0.8 \\
$\mathrm{p}_{3}$ & 1.0 & 0.0 & -0.8 & $\mathrm{p}_{12}$ & 0.0 & 0.0 & 0.8 \\
$\mathrm{p}_{4}$ & 1.0 & 1.0 & -0.8 & $\mathrm{p}_{13}$ & -1.0 & -1.0 & 0.8 \\
$\mathrm{p}_{5}$ & 1.0 & 1.0 & 0.8 & $\mathrm{p}_{14}$ & -1.0 & -1.0 & -0.8 \\
$\mathrm{p}_{6}$ & 1.0 & 0.0 & 0.8 & $\mathrm{p}_{15}$ & -1.0 & 0.0 & -0.8 \\
$\mathrm{p}_{7}$ & 0.0 & -1.0 & 0.8 & $\mathrm{p}_{16}$ & -1.0 & 1.0 & -0.8 \\
$\mathrm{p}_{8}$ & 0.0 & -1.0 & -0.8 & $\mathrm{p}_{17}$ & -1.0 & 1.0 & 0.8 \\
$\mathrm{p}_{9}$ & 0.0 & 0.0 & -0.8 & $\mathrm{p}_{18}$ & -1.0 & 0.0 & 0.8 \\
\hline
\end{tabular}

It can be found that the maximum value of the maximum principal stress $\sigma_{1}$ at the point $\mathrm{p}_{6}, \mathrm{p}_{12}, \mathrm{p}_{15}$ is the largest at each plane (upper, middle and lower), respectively. Among them, the maximum value at the point $\mathrm{p}_{15}$ is the largest [35.88 MPa, as shown in Fig. 9 (c)]. Furthermore, the three points $\left(\mathrm{p}_{6}, \mathrm{p}_{12}\right.$ and $\left.\mathrm{p}_{15}\right)$ are all located in the plane where $y / w=0.0$. Thus, the vertical middle plane $(y / w=0.0)$ is chosen to examine the stress wave propagations and stress distributions of the single-lap adhesive joint with dissimilar adherends (aluminum-steel) subjected to the impact tensile loadings in this study. For examining the stress distributions at the interfaces, upper interface (aluminum side, $\mathrm{p}_{6}-\mathrm{p}_{3}$, solid line), middle plane (in the adhesive layer, $\mathrm{p}_{12}-\mathrm{p}_{9}$, dash line) and lower interface (steel side, $\mathrm{p}_{18}-\mathrm{p}_{15}$, dotted line) are chosen, which also as shown in Fig. 10.

Fig. 10 shows the maximum principal stress $\sigma_{1}$ distributions at the upper interface ( $t=0.132 \mathrm{~ms}$, when the maximum value of the maximum principal stress $\sigma_{1}$ at point $\mathrm{p}_{6}$ occurs), middle plane $(t=0.117 \mathrm{~ms}$, when the maximum value of the maximum principal stress $\sigma_{1}$ at point $\mathrm{p}_{12}$ occurs) and lower interface $(t=0.069 \mathrm{~ms}$, when the maximum value of the maximum principal stress $\sigma_{1}$ at point $\mathrm{p}_{15}$ occurs). The abscissa is the position described by the normalized value $z / l_{2}$ and the ordinate is the value of the maximum principal stress $\sigma_{1}$. It is observed that the stress increases as the position close to the interface edges, which is one of the main reasons to cause the rupture of the joint due to the steep stress near the edges of interfaces $[34,35]$. The value of the stress near the interface edge $\left(z / l_{2}=-0.8\right)$ at the lower interface (steel side) is the largest. During the stress wave propagations, the extents of the wave impedance mismatch are different between the two interfaces (aluminum side and steel side) bonded with adhesive owing to the different material properties of the adherends. The wave impedance mismatch of the steel to the adhesive is larger than that of the aluminum to the adhesive, which is the assumed reason for leading to the larger stress at the steel side in the joint under impact loadings. It can be assumed that the rupture initiates near the interface edge at the lower interface, which of the adherend with the higher Young's modulus (steel side), in the single-lap adhesive joint with dissimilar adherends (aluminum-steel) subjected to the impact tensile loadings. This result is opposite to that of the single-lap adhesive joint with dissimilar adherends subjected to the static tensile loadings, which the maximum value of the maximum principal stress occurs near the interface edge of the adherend with the smaller Young's modulus [4].

Fig. 11 shows the effects of Young's modulus ratio $E_{1} / E_{3}$ on the maximum principal stress $\sigma_{1}$ wave propagations at the two key points $\left(\mathrm{p}_{6}\right.$ and $\left.\mathrm{p}_{15}\right)$ [Fig. 11(a)] and the maximum principal stress $\sigma_{1}$ distributions (at the upper and lower interfaces) [Fig. 11(b)]. Young's modulus of the adhesive layer [II] $E_{2}$ and that of the adherend [I] are held constant as $3.34 \mathrm{GPa}$ and $70 \mathrm{GPa}$, respectively. Young's modulus of the adherend [III] $E_{3}$ is chosen as $206 \mathrm{GPa}, 140 \mathrm{GPa}$ and $70 \mathrm{GPa}$ (similar adherends condition), respectively. Correspondingly, Young's modulus ratio $E_{1} / E_{3}$ varies as $0.34,0.5$ and 1.0 , respectively.

In Fig. 11(a), the abscissa is the elapsed time $t$ simulated in FEM calculations and the ordinate is the values of the maximum principal stress $\sigma_{1}$ at different points. It is found that the maximum principal stress $\sigma_{1}$ increases as Young's modulus ratio $E_{1} / E_{3}$ increases at the point $\mathrm{p}_{6}$, which is at the upper interface (aluminum side). However, the effect is very small. In addition, it can be found that the maximum principal stress $\sigma_{1}$ increases as Young's modulus ratio $E_{1} / E_{3}$ decreases at the point $\mathrm{p}_{15}$, which is at the lower interface (steel side). Furthermore, it can be found that the time point when the peak value of the maximum principal stress $\sigma_{1}$ occurs is later when Young's modulus of adherend [III] $E_{3}$ smaller at point $\mathrm{p}_{15}$. The reason is assumed that the extent of the wave impedance mismatch decreases as the adherend [III] Young's modulus $E_{3}$ decreases with respect to that of the adhesive. Moreover, the abscissa $z / l_{2}$ in Fig. 11(b) is the position and the ordinate is the value of the maximum principal stress $\sigma_{1}$, the maximum values of the stresses can be seen near the interface edges.

It can be concluded that the rupture initiates at the interface where Young's modulus of the adherend in the joint under impact tensile loadings is larger (steel side in this study) with higher extent of the wave impedance mismatch to the adhesive layer. Furthermore, when Young's modulus ratio $E_{1} / E_{3}$ approaches 1.0, the joint strength increases as the maximum value of stress decreases near the interface edges. It can be concluded that the strength of the joint with dissimilar adherends is smaller than that of the joint with similar adherends.

\subsection{Discussion}

According to our previous investigation [28], it can be obtained that the maximum principal stresses near the interface edges increase as the initial impact velocity $V$ increases owing to the 

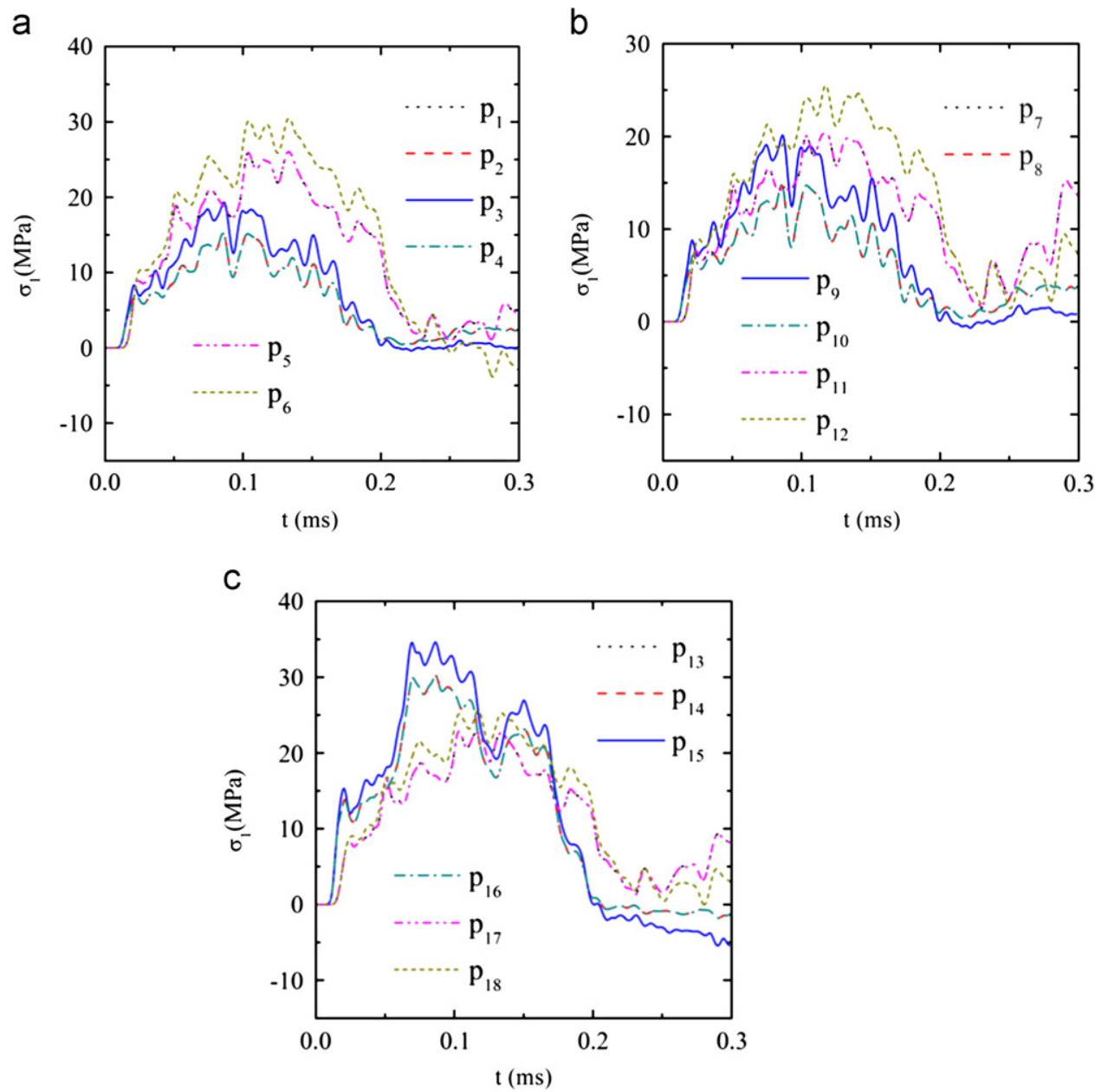

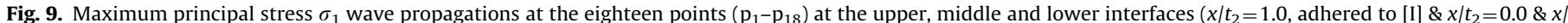

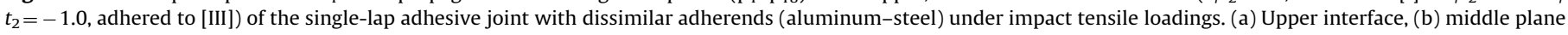
and (c) lower interface.

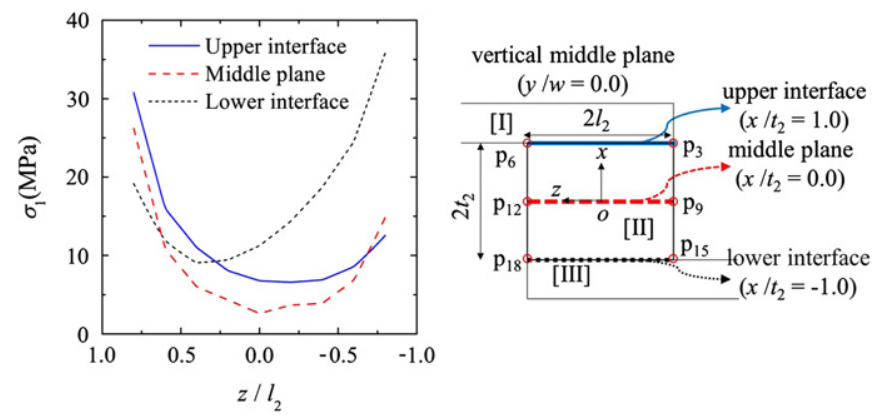

Fig. 10. Maximum principal stress $\sigma_{1}$ distributions through the upper, middle and lower interfaces in the single-lap adhesive joint with dissimilar adherends (aluminum-steel) under impact tensile loadings.

increment of the impact energy. When the initial impact velocity $V$ as small as possible even approaches zero as a special case, the external loading can be considered as a sudden loading instead of static loading.

When the joint with dissimilar adherends (aluminum-steel) subjected to the static tensile loadings, the static force is defined as the same external force with that of the joint subjected to the sudden loadings. Using static and impact subroutines, the static and dynamic performances of the joint can be calculated, respectively. Sawa et al. [4] have examined the single-lap adhesive joint with dissimilar adherends under static loadings with the conclusions that the rupture initiates at the interface of the adherend with smaller Young's modulus (aluminum side in this study). Thus, the interface of the adherend with smaller Young's modulus (aluminum side, upper interface) is chosen to examine the interface stress distributions of the joint under static tensile loadings.

Fig. 12 shows the comparison of the interface stress distributions at the upper and lower interfaces (as shown in Fig. 10) between the joint with dissimilar adherends (aluminum-steel) subjected to the impact (sudden loadings) and static tensile loadings. It can be observed that when the initial impact velocity $V$ indefinitely approaches zero, the peak stress value at the lower interface (steel side) is larger than that at the upper interface (aluminum side). In addition, it can be found that the values of the maximum principal stress $\sigma_{1}$ distributions of the joint subjected to the impact tensile loadings (sudden loadings) is larger than those of the joint subjected to the static loadings.

Based on the comparison between the characteristics of the single-lap adhesive joint with dissimilar adherends (aluminumsteel) subjected to the impact and static loadings, it can be found that the positions of the rupture initiation are different, which at the interface of the adherend with higher Young's modulus (steel side) of the joint subjected to the impact loadings because of the larger extent of the wave impedance mismatch to the adhesive layer and at the interface of the adherend with smaller Young's modulus (aluminum side) of the joint subjected to the static loadings, respectively. 
a
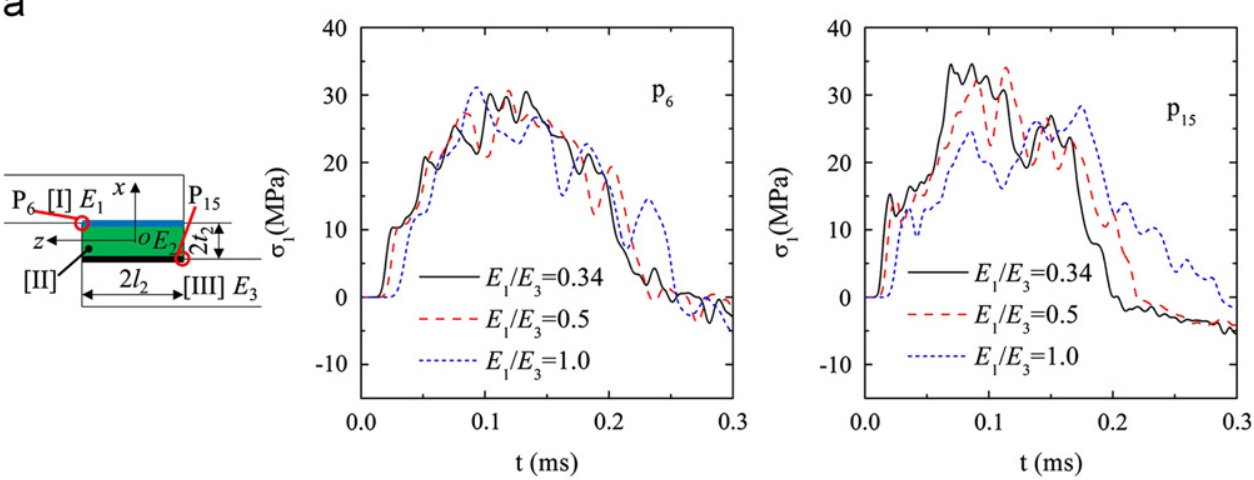

b

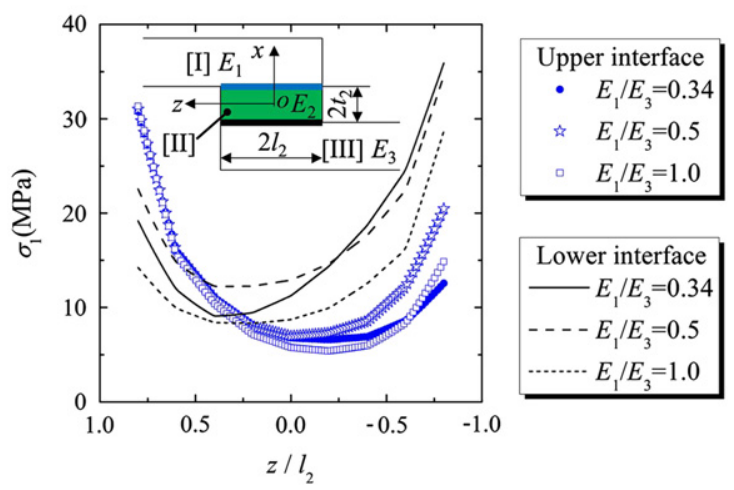

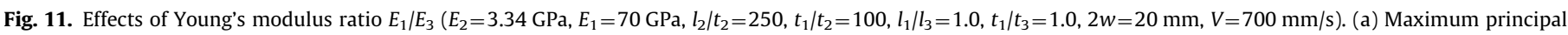

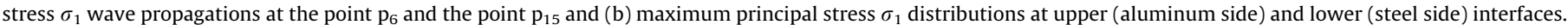

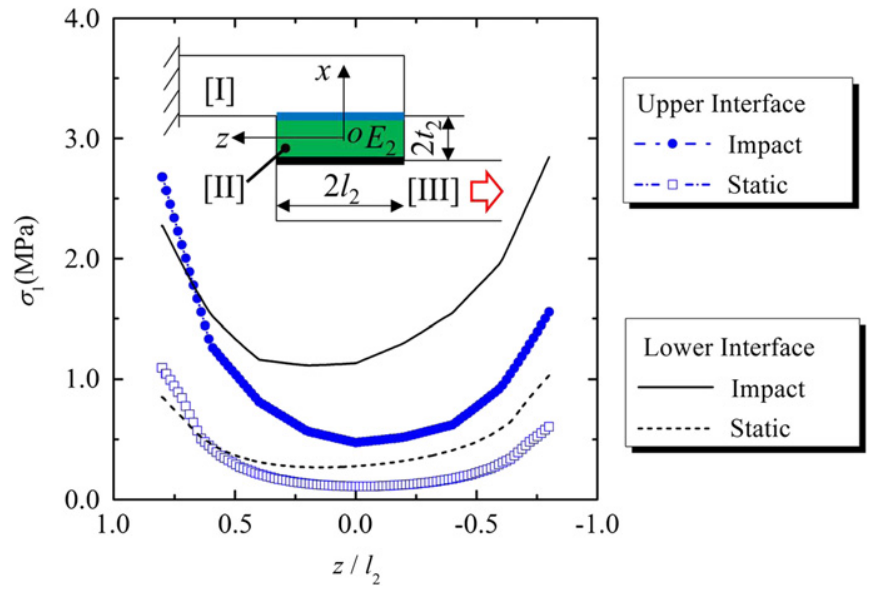

Fig. 12. Comparison of the maximum principal stress $\sigma_{1}$ distributions at the upper and lower interfaces of the single-lap adhesive joint with dissimilar adherends (aluminum-steel) under impact tensile loadings (sudden loadings) with those of the joint under static tensile loadings.

Table 5 shows the guideline for designing the single-lap adhesive joint with similar and dissimilar adherends subjected to the static and impact tensile loadings. Each component and position is as shown in Figs. 4 and 8.

\section{Conclusions}

In this study, the strain responses and strengths of the singlelap adhesive joint with dissimilar adherends (aluminum-steel) subjected to the impact tensile loadings were measured experimentally. In addition, the stress wave propagations and interface stress distributions of the joint are analyzed using 3D FEM
Table 5

Guideline for designing single-lap adhesive joint with similar and dissimilar adherends under static and impact tensile loadings.

\begin{tabular}{|c|c|c|}
\hline \multirow[t]{2}{*}{ objects } & \multicolumn{2}{|l|}{ Joint types } \\
\hline & $\begin{array}{l}\text { Similar adherends } \\
\left(E_{1}=E_{3}\right) \\
E_{1} \uparrow\end{array}$ & $\begin{array}{l}\text { Dissimilar adherends }\left(E_{1} \neq E_{3}\right) \\
\text { Difference }\left(E_{1} \& E_{3}\right) \uparrow\end{array}$ \\
\hline \multicolumn{3}{|c|}{ Static tensile loadings } \\
\hline$\sigma_{1}$ & $\downarrow[35]$ & $\uparrow[4]$ \\
\hline Strength & $\uparrow[35]$ & $\downarrow[4]$ \\
\hline Rupture & $y / w=0.0$ & $y / w=0.0$ Upper interface (smaller \\
\hline $\begin{array}{l}\text { initiated } \\
\text { position }\end{array}$ & $\begin{array}{l}\text { Upper and lower } \\
\text { interfaces: } x / t_{2}= \pm 1.0 \\
{[35]}\end{array}$ & Young's modulus side): $x / t_{2}=1.0$ \\
\hline \multicolumn{3}{|c|}{ Impact tensile loadings } \\
\hline$\sigma_{1}$ & $\uparrow[28]$ & $\uparrow$ \\
\hline Strength & $\downarrow[28]$ & $\downarrow$ \\
\hline Rupture & & $y / w=0.0$ Lower interface (Higher \\
\hline $\begin{array}{l}\text { initiated } \\
\text { position }\end{array}$ & & Young's modulus side): $x / t_{2}=-1.0$ \\
\hline
\end{tabular}

calculations taking into account the strain rate dependency of the adhesive, which the required material parameters are obtained from the experimental results. The following results are obtained.

(1) Adhesive rate dependency can be expressed using CowperSymonds model simulations appropriately.

(2) The experimental and FEM calculated results demonstrate that the rupture initiates at the interface of the adherend with higher Young's modulus (steel side in this study) in the single-lap adhesive joint with dissimilar adherends (aluminum-steel) subjected to the impact tensile loadings, which shows the opposite characteristic of that the rupture initiates in the vicinity of the interface edge of the adherend with smaller Young's modulus 
(aluminum side in this study) in the same type joint under static loadings. A fairly good agreement is observed between the experimental measured and the FEM calculated results.

(3) It can be concluded that the strength of the joint with dissimilar adherends is smaller than that of the joint with similar adherends.

(4) The value of the maximum principal stress $\sigma_{1}$ is larger when the joint is subjected to the sudden tensile loadings ( $V$ converges towards zero) than that of the joint subjected to the static tensile loadings. In addition, the peak stress value at the interface of the higher Young's modulus adherend (steel side) is larger than that at the interface of the smaller Young's modulus adherend (aluminum side) of the joint under sudden loadings. However, the characteristic of the joint subjected to the static loadings is different. In such case, the peak stress value at the interface of the higher Young's modulus adherend (steel side) is smaller than that at the interface of the smaller Young's modulus adherend (aluminum side).

(5) The design guideline for the single-lap adhesive joint is summarized and provided to supply the references under various conditions.

\section{Acknowledgements}

This research, which is under experimental supports and valuable technical guidance from Prof. Sawa Toshiyuki and his team of Hiroshima University in Japan, is also supported by the National Natural Science Foundation of China, Grant No. 11202222.

\section{References}

[1] Adams RD, Comyn J, Wake WC. Structural adhesive joints in engineering. 2nd ed.. London: Chapman \& Hall; 1997 12-118.
[2] Raykhere Sohan Lal, Kumar Prashant, Singh RK, Parameswaran Venkitanarayanan. Mater Des 2010;31(4):2102-9.

[3] Sawa T, Temma K, Tsunoda Y. Int J Adhes Adhes 1989;9(3):161-9.

[4] Sawa T, Liu J, Nakano K, Tanaka J. J Adhes Sci Technol 2000;14(1):43-66.

[5] Sawa T, Ichikawa K, Shin Y, Kobayashi T. Int J Adhes Adhes 2010;30(5): 298-305.

[6] Harris JA, Adams RD. Proc Inst Mech Eng 1985;199(C2):121-31.

[7] Adams RD, Harris JA. Int J Adhes Adhes 1996;16:61-71.

[8] Sato C, Ikegami K. J Adhes 1999;70(1 \& 2):57-73.

[9] Sato C, Ikegami K. Int J Adhes Adhes 2000;20:17-25.

[10] Sato C. Int J Adhes Adhes 2009;29:670-7.

[11] Yokoyama T, Shimizu H. JSME Int J, Ser A 1998;41(4):503-9.

[12] Yokoyama T. J Strain Anal 2003;38:233-45.

[13] Higuchi I, Sawa T, Suga H. J Adhes Sci Technol 2002;16(12):1585-601.

[14] Sawa T, Higuchi I, Suga H. J Adhes Sci Technol 2003;17(16):2157-74.

[15] Higuchi I, Sawa T, Okuno H, Kato S. J Adhes 2003;79:1017-39.

[16] Sawa T, Suzuki Y, Kido S. J Adhes Sci Technol 2002;16(11):1449-68.

[17] Sawa T, Suzuki Y, Kido S. J Adhes Sci Technol 2003;17(7):943-65.

[18] Maheri MR, Adams RD. Int J Adhes Adhes 2002;22(2):119-27.

[19] Vaidya UK, Gautam ARS, Hosur M, Dutta P. Int J Adhes Adhes 2006;26(3): 184-98.

[20] Goglio L, Rossetto M. Int J Impact Eng 2008;35:635-43.

[21] Challita G, Othman R. Int J Adhes Adhes 2010;30:236-44.

[22] $3 \mathrm{M}^{\mathrm{TM}}$ scotch-weld ${ }^{\mathrm{TM}}$ epoxy adhesive $1838 \mathrm{~B} / \mathrm{A}$, product catalog for industrial adhesives, engineered adhesives division, 3M, 2002.

[23] Ichikawa K, Shin Y, Sawa T. Int J Adhes Adhes 2008;28:464-70.

[24] Cowper GR, Symonds PS. Brown Univ Appl Math Rep 1958:28.

[25] Iwamoto T, Nagai T, Sawa T. Int J Solid Struct 2010;47:175-85.

[26] Nagai T, Iwamoto T, Sawa T, Sekiguchi Y, Kuramoto H, Uesugi N. Engineering plasticity and its applications from nanoscale to macroscale. In: Proceedings of the ninth AEPA; 2008. p. 218-223.

[27] Nagai T. A study on finite-element analyses and strength of adhesive joints subjected to impact loadings. Master thesis and presentation. Hiroshima University, Japan; 2009.

[28] Liao L, Kobayashi T, Sawa T, Goda Y. Int J Adhes Adhes 2011;31(7):612-9.

[29] Liao L, Sawa T, Hasegawa T. JSME J Sol Mech Mater Eng 2010;4(6):621-37.

[30] Liao L, Sawa T, Hasegawa T. JSME J Sol Mech Mater Eng 2010;4(7):988-98.

[31] Sancaktar E, Narayan K. J Adhes Sci Technol 1999;13(2):237-71.

[32] Kilic B, Madenci E, Ambur DR. Eng Fract Mech 2006;73:1472-90.

[33] Goglio L, Rossetto M. Int J Adhes Adhes 2010;30:313-21.

[34] Andreas Öchsner, da Silva Lucas FM, Adams RD. Complex joint geometry. In: da Silva Lucas FM, Andreas Öchsner, editors. Modeling of adhesively bonded joints. Verlag Berlin Heidelberg: Springer; 2008. p. 131-50.

[35] Sawa T, Nakano K, Toratani H. J Adhes Sci Technol 1997;11(8):1039-62. 